\title{
DESVINCULAÇÃO ENTRE AVALIAÇÃO E ATRIBUIÇÃO DE NOTA: ANÁLISE DE UM CASO NO ENSINO DE FÍSICA PARA FUTUROS PROFESSORES
}

\section{DESVINCULAÇÃO BETWEEN ASSESSMENT AND GRADING: AN ANALYSIS OF A CASE IN PHYSICS EDUCATION FOR FUTURE TEACHERS}

\author{
João Batista Siqueira Harres \\ UNIVATES Centro Universitário de Lajeado \\ E-mail: ibharres@univates.br
}

\section{Resumo:}

Este trabalho relata uma proposta de avaliação adotada com futuros professores em uma disciplina de física na qual a avaliação não tem relação com a nota (classificação). Esta proposta está integrada a uma perspectiva didática mais ampla na qual pretende-se que os alunos assumam um papel ativo na disciplina. Parte-se do princípio de que na formação inicial de professores a busca da autonomia e da responsabilidade pela própria aprendizagem está condicionada a vivencia de um ambiente que favoreça o desenvolvimento da auto-avaliação para o qual considera-se que o processo de atribuição de nota é um obstáculo. Vinculado a um processo investigativo mais amplo de formação, apresenta-se os fundamentos e as estratégias da postura de não julgar o conhecimento dos alunos e as características do processo avaliativo não sancionador, processual e formativo. Ao final, são apresentadas algumas manifestações desses futuros professores sobre a experiência vivida e uma escala de evolução das práticas avaliativas que orienta o processo formativo.

Palavras-chave: Formação de professores, avaliação, processo formativo.

\section{Abstract:}

This work describes a proposal for evaluation adopted with future teachers in one discipline of physics in which the assessment does not have a relationship with the grade (classification). This proposal is integrated to a broader didactic perspective that aims that pupils assume an active role in the discipline. We have as principle the notion that in pre-service teacher education the search for autonomy and responsibility for their own learning is conditioned to experiencing an environment that favors the development of self-assessment, for which grading is considered an obstacle. Tied to a broader process of education, we present the basis and the strategies for taking position and not judging pupils' knowledge, as well as the characteristics of the assessment that doesn't sanction but focus on process and is formative. We conclude presenting some these future teachers' ideas on the lived experience and a scale of the evolution of the practical assessment that guides the formative process.

Key-words: Teacher training , assessment, formative process 


\section{1- INTRODUÇÃO}

Como parte de uma pesquisa maior sobre inovações na formação de professores, vimos investigando como três aspectos distintos favorecem o desenvolvimento profissional inicial de professores em direção ao modelo de referência proposto por Porlán e Rivero (1998): (i) a inclusão das perspectivas históricas e epistemológicas evolutivas na abordagens do conteúdos (García, 1998 e Porlán e Harres, 1999); (ii) o desenvolvimento de metodologias ativas baseadas na explicitação e evolução das próprias idéias (Cubero, 1989 e Harres, 2003); (iii) e, tema central deste trabalho, a implementação de uma avaliação não sancionadora, processual e formativa orientada para a responsabilidade pela própria aprendizagem (Harres, 2002a).

Entre as muitas dificuldades e obstáculos para uma mudança na sala de aula, pode-se apontar a cultura tradicional na qual os alunos desempenham um papel passivo e os professores um papel ativo, quase obsessivo muitas vezes. Para ajudar a superar esse obstáculo, a investigação de casos em que futuros professores vivenciam uma cultura alternativa pode ser muito útil. Isto é possível porque, de um lado e perfeitamente plausível transferir os resultados do contexto universitário para o contexto escolar porque os professores, em geral, iniciam sua formação profissional no mesmo nível de conhecimento que seus futuros alunos (Harres, 2001). Por outro lado, é pouco provável que professores que não tenham vivido em sua formação experiências alternativas, especialmente em relação à avaliação, possam espontaneamente desenvolve-las mais tarde na escola (Nóvoa, 2001).

Infelizmente, o debate sobre avaliação ainda é incipiente nos âmbitos dos espaços de debate e investigação. Apesar de ser um problema e um conflito antigos, parece não haver ainda uma cultura geral de avaliação com o mesmo nível de desenvolvimento, em termos investigativos, de outros aspectos do ensino.

Se através de nossas aulas desejamos propiciar uma cultura alternativa aos estereótipos sócio-culturais dominantes, apenas mudanças didáticas superficiais não bastam. Provavelmente, será muito difícil transformar a educação em direção a uma perspectiva mais humanista e não autoritária sem rompermos com as práticas avaliativas que, ao final, sempre acabam "medindo" o conhecimento do outro. Mesmo quando se pratica uma avaliação mais ampla, por exemplo, incluindo procedimentos e atitudes, o resultado final do processo educativo, muitas vezes, ainda se reflete em um número (ou conceito) que classifica, diferencia ou discrimina os estudantes. Sem mudar esse aspecto tão condicionante das atitudes dos alunos será possível um desenvolvimento amplo da autonomia?

\section{2-CONTEXTO}

Trata-se de duas disciplinas (Física II e Física III) de introdução à mecânica, com 60 horasaula cada uma, e parte de um curso de cinco anos que habilita (de forma integrada) professores para as disciplinas de Física, Química e Matemática. Esta integração de habilitações em geral oferecidas separadamente favorece a formação de professores em uma perspectiva interdisciplinar da futura ação docente. Além disso, a estrutura curricular também se diferencia por oferecer, já no seu início, uma série de disciplinas que pretendem aproximar o estudante da sua futura prática profissional (Harres e Pizzato, 2003). 
Com tudo isso, pretende-se atender à necessidade de formar os futuros professores em um contexto alternativo àquele vivenciado preponderantemente em sua vida estudantil. Esta perspectiva, consenso geral no âmbito das didáticas específicas (Martín del Pozo e Porlán, 2000), está agora manifesta também nas recentes diretrizes estabelecidas para a formação de professores no Brasil.

\section{3-METODOLOGIA}

Coerente com tudo isso, pretende-se que a Física seja concebida, conforme propõe, García (1998), como uma versão não simplificada do conhecimento científico, oriunda de diferentes fontes (conhecimento disciplinar, conhecimentos alternativos dos alunos, conhecimentos didáticos gerais e específicos) e formulada em uma perspectiva evolutiva desde os níveis (do conhecimento) mais simples até outros mais complexos.

As disciplinas estão estruturadas para desenvolver a auto-responsabilidade pela própria aprendizagem e o desenvolvimento da capacidade de aprender a aprender. A seguir, descreve-se os pressupostos adotados para favorecer esse processo que constituem as idéias-força em investigação no processo formativo.

O primeiro pressuposto, de natureza atitudinal, talvez o mais importante, refere-se ao fato de que, embora haja a explicitação das concepções finais desejadas sobre os conteúdos, nenhum aluno é reprovado por apresentar, ao final, uma concepção diferente da esperada. Concretamente, trabalha-se para a aceitação das leis de Newton como a concepção, neste momento, mais avançada para a interpretação das situações cotidianas, mas ninguém é reprovado se apresentar ao final, por exemplo, a concepção aristotélica sobre força e movimento. Enfim, ninguém é punido por não alcançar os objetivos conceituais ou, do ponto de vista do aluno, por pensar diferente do professor.

É interessante notar que, a rigor, é isto que ocorre em muitos casos, tanto no ensino de física universitário como nas escolas, sem que sejamos conscientes. Ou seja, a maioria dos alunos é promovida (alguns inclusive tornam-se professores) apenas aparentando ter domínio da mecânica newtoniana. Porém, quando se lhes pergunta sobre o que de fato pensam a respeito e não sobre 0 que lhes explicaram na escola, o resultado é outro (Harres, 2003). Prova disso, são as inúmeras pesquisas atestando a incompreensão das relações sobre força e movimento de estudantes ao fim do ensino médio (Villani e Polido Ferreira, 1997; Thorton e Sokoloff, 1998) e também de estudantes já em nível de graduação (Moraes e Moraes, 2000) e pós-graduação (Neves e Savi, 1999).

A postura de avaliar sem punir é explicitada já nas primeiras aulas deixando-se claro que o professor abdica de ser o juiz do conhecimento dos alunos. A explicitação preliminar desse princípio visa criar o clima desejável para a implementação do segundo pressuposto, de natureza procedimental. Durante as aulas, espera-se que os alunos exponham, analisem e façam um acompanhamento das suas próprias idéias sem sentirem-se pressionados a dar "a" resposta que o professor espera. Ou seja, cada aluno é incentivado a desenvolver a capacidade de ser responsável pela sua própria aprendizagem. Para isso, o caderno de trabalho pessoal desempenha um papel fundamental como ferramenta para o auto-acompanhamento da evolução individual.

Didaticamente, sempre se adota como ponto de partida uma reflexão individual sobre as próprias idéias nos conceitos envolvidos. Após essa reflexão, os estudantes contrastam as idéias explicitadas em pequeno e grande grupo, para logo em seguida buscarem-se experimentos, livros 
de texto, episódios da história da ciência e outras fontes de conhecimentos que favoreçam a evolução conceitual.

Aqui, a perspectiva histórica e a perspectiva epistemológica do conhecimento científico são fundamentais. No caso das concepções sobre força e movimento analisa-se como essas idéias foram evoluindo ao longo da história. Parte-se, conforme propõe Peduzzi (1996), da concepção aristotélica, passando pela física da força impressa, desenvolvida na Idade Média, e chega-se até òs Leis de Newton.

Cabe destacar que, na tentativa de superar os problemas apontados por Solano e outros (2000) no tratamento das concepções dos alunos sobre força, estas não são analisadas unicamente desde o ponto de vista (em geral absolutista) do conhecimento acadêmico. A análise leva em consideração principalmente a sua correlação com um modelo de evolução histórico de referência que, por sua vez, é contrastado também com evidências empíricas construídas pela análise de situações concretas (por exemplo, corpos deslocando-se sobre superfícies sem atrito). Os dados que temos colhido, analisados em outra pesquisa (Harres, 2002b), indicam, como defende Marin (2002), que esta pode ser uma razão importante pela qual as pesquisas sobre estratégias para evolução das idéias dos alunos sobre força e movimento têm registrado pequeno avanço.

De fato, nossas análises mostram um espectro diferente daquele geralmente apontado por pesquisas de revisão na área (Solano e outros, 2000). Já a partir das primeiras atividades percebese que as concepções dos alunos parecem se adequar mais a concepções mistas entre as aristotélicas e as newtonianas. Em outras palavras, entre essas visões bastante antagônicas, encontramos, como sugerem Peduzzi e Zylberstajn (1997), um estágio conceitual intermediário bastante consistente que é análogo às concepções medievais sobre força e movimento e coerente com a evolução histórica dessas idéias.

Para o acompanhamento da evolução das idéias dos alunos construíu-se uma escala evolutiva, detalhada em Harres (2002b) e mostrada no quadro abaixo, que, sem pretender ser totalmente fiel à história, estabelece a hipótese de progressão (García e Porlán, 2000) desse conhecimento em torno qual os futuros professores avaliar-se-ão.

Quadro no 1 - Níveis de evolução das concepções sobre força e movimento

\begin{tabular}{|c|l|c|}
\hline Nível & \multicolumn{1}{|c|}{ Característica } & Concepção \\
\hline 1 & $\begin{array}{l}\text { O repouso é o estado natural dos corpos. A força do ar (' antiperistasis' } \\
\text { mantém os movimentos por mais algum tempo após lançamento. } \\
\text { Depois, a gravidade e o atrito fazem os corpos pararem. }\end{array}$ & Aristotélica \\
\hline 2 & A força impressa, que mantém o movimento, diminui naturalmente. & Medieval Inicial \\
\hline 3 & A força impressa é diminuída pela ação do atrito. & Medieval Mista \\
\hline 4 & A força impressa e o atrito atuam. & Medieval Pré-inercial \\
\hline 5 & $\begin{array}{l}\text { Os corpos não necessitam de força para manterem-se em movimento. } \\
\text { Eles param porque alguma força contrária atua. }\end{array}$ & Inercial \\
\hline
\end{tabular}

Em termos epistemológicos, a apresentação da evolução dessas idéias não é feita considerando que o conhecimento "correto" substitui o conhecimento "errado", mas sim tentando-se agregar permanentemente ao trabalho o caráter não acabado, limitado e construtivo de qualquer concepção (inclusive a concepção newtoniana) sobre força e movimento. As concepções aceitadas no passado são trabalhadas sempre contextualizando a sua construção e destacando que tipo de problemas resolvia e/ou pretendia resolver. Mesmo a perspectiva newtoniana de força e movimento 
é tomada de modo evolutivo e provisória pois são realizadas leituras das limitações da mecânica newtoniana (teoria da relatividade, por exemplo) e de outras propostas atualmente em discussão no meio científico que apresentam outras explicações para os fenômenos estudados (Assis, 1998). Assim, busca-se a superação das visões epistemológicas absolutistas do conhecimento científico tão comuns entre professores da área (Harres, 1999).

Ao mesmo tempo, essa abordagem ajuda a que os futuros professores, ao identificarem as dificuldades de aceitação dessas idéias na comunidade científica, associem-nas as suas próprias dificuldades de evolução conceitual, desenvolvendo também a postura positiva de compreensão das dificuldades dos seus futuros alunos. Maiores detalhes das atividades e das estratégias para acompanhamento e avaliação da evolução conceitual dos alunos podem ser encontrados em Harres (2003).

Porém, acredita-se que estes princípios têm pouca validade se o conhecimento trabalhado não estiver conectado ativamente com a relevância e a adequação do nível de formulação do contexto formativo a que se destina. Assim, mesmo em uma disciplina cujo papel dentro do currículo formativo esteja centrada nos "conteúdos", discute-se e trabalha-se enfaticamente a forma como esses "conteúdos" foram trabalhados com eles mesmos enquanto estudantes do ensino médio, como esses "conteúdos" aparecem nos livros didáticos e, ainda, que importância eles tem na vida cotidiana e na formação do cidadão.

\section{4 - DESVINCULAÇÃO ENTRE AVALIAÇÃO E CLASSIFICAÇÃO (ATRIBUIÇÃO DE NOTAS)}

Os problemas da avaliação tradicional são já bastante conhecidos. Eles podem ser sintetizados em dois grandes dilemas. De um lado, é difícil garantir que a informação obtida sobre o pensamento do estudante corresponda realmente ao que ele pensa ou que esteja livre da influência de posturas adaptativas de sobrevivência no contexto. Dito de forma mais direta, geralmente a avaliação tradicional identifica a presença ou não de saberes retidos apenas para obter aprovação. Ela não favorece o desenvolvimento da consciência sobre o que se sabe e sobre o que não se sabe. Conseqüentemente, obtém-se falta de autonomia e uma atitude de sempre esperar por uma avaliação externa cujo resultado é uma pequena responsabilidade pela própria aprendizagem.

Mesmo supondo que as posturas adaptativas possam ser eliminadas, tem-se ainda dificuldades de ordem processual porque não é possível garantir que o pensamento do aluno daquele momento se mantenha inalterado ao longo do tempo. Se o aluno hoje demonstra saber algo, ele pode mais tarde, como ocorre muitas vezes, acabar "esquecendo" aquilo que foi ensinado. Se ele demonstra não saber algo hoje, é bem possível que mais cedo ou mais tarde venha a entender o que antes não entendia.

E mais, mesmo que desconsideremos a possibilidade sempre presente de que 0 conhecimento "errado" de hoje venha a ser o "correto" de amanhã e viceversa, pode até não ser desejável que o seu conhecimento se mantenha inalterado. Por exemplo, quando um aluno afirma que os corpos tendem a parar uma vez cessada a ação motora que iniciou o movimento, provavelmente o ensino tradicional (absolutista) apontará que seu pensamento está errado e lhe transmitirá a idéia de que um corpo, sem a influência de forças externas, se moverá indefinidamente em linha reta com velocidade constante (1 ${ }^{\underline{a}}$ Lei de Newton). Em outras palavras, se insistirá que a tendência dos corpos é permanecerem em movimento sem que nada seja necessário para mantê- 
los assim. Petrosino (2000), em um caso análogo, sustenta que este aluno, apenas repetindo o que o professor lhe transmitiu, agora sabe menos que antes, pois sobre este último conhecimento ele não pode operar, não coincide com que ele vê, não tem motivos para acreditar nele e se o aceita estará destruindo a confiança em seu próprio esforço para entender o mundo. Definitivamente, um mal modelo é melhor que nenhum modelo (p.86).

Assim, pode-se afirmar que os problemas da avaliação tradicional estão associados a uma visão simplista da aprendizagem e uma visão absolutista do conhecimento. Para superarmos estes problemas, propomos a adoção de uma avaliação não sancionadora, processual e formativa. Em primeiro lugar, o caráter não sancionador da avaliação na disciplina se concretiza pelo fato de atribuir-se a mesma "nota" a todos os alunos sem exceção, independentemente do nível de evolução conceitual alcançado. A aprovação está condicionada apenas à freqüência mínima de $75 \%$ das aulas.

Em segundo lugar, a avaliação é processual porque, a cada nova atividade, os alunos devem auto-avaliar-se em relação à escala de evolução conceitual que vai sendo construída. Nesse processo, avanços e retrocessos são muito comuns. Por exemplo, alguns alunos apresentam concepções muito próximas das concepções newtonianas nas primeiras reflexões individuais e, mais tarde, pela interação com os colegas e pela postura do professor de não identificar essa concepção como "correta", esses alunos defendem posições que sugerem uma grande fragilidade na compreensão apresentada anteriormente.

No final, procura-se favorecer que o próprio estudante seja consciente de porque essas variações ocorrem, identificando o estágio da própria evolução e as idéias que ainda podem (devem) ser modificadas. Como exemplo, podemos citar a difícil superação da idéia de força como "algo que se transfere de um corpo a outro" pela idéia de força como "interação entre dois corpos".

Por último, acredita-se que o caráter formativo da avaliação é mais conseqüência de toda a postura anteriormente delineada do que propriamente um novo aspecto a ser analisado isoladamente. Como evidencia disso, a seguir são apresentadas algumas auto-avaliações dos futuros professores escritas ao final do estudo sobre força e movimento. De acordo com os objetivos do processo formativo mais amplo no qual estão inseridos, estas manifestações, transcritas de alguns cadernos de trabalho pessoal recolhidos aleatoriamente, permitem uma avaliação sobre o avanço obtido no desenvolvimento da capacidade de auto-avaliar-se e de ser agente da própria aprendizagem.

"Não me preocupo com a nota, me preocupo em aprender. Aprendi muito em grupo, onde um clareava as idéias do outro, sempre construindo mais. Aprendi muito sobre a história da física, onde conseguimos ver o início dos grandes problemas e dilemas físicos não resolvidos até hoje."

"[Houve] mais interesse, mais participação. Nada foi feito por obrigação, tudo por vontade [própria]. Cada um faz a sua aprendizagem. Aprendi a valorizar minhas idéias e não apenas substituílas pelas do professor. O que menos gostei é que professor não dizia se nossas idéias estavam certas ou erradas, deixando dúvidas."

"A nota, às vezes, atrapalha porque ficamos preocupados com ela e não com o assunto. Essa maneira de avaliar é legal já que o quanto aprendemos não tem muitas vezes nada tem a ver com a nota. Além disso cada um de nós tem a consciência de que precisamos entender e buscar superar nossos limites. Sem a pressão da nota aprendemos mais, ou seja, cada um é responsável pela sua aprendizagem. Aprendi a buscar o conhecimento com autonomia, valorizando minhas idéias e respeitando as dos outros."

"Adoro esse método de avaliação. Nos deixa livres para a aprender sem pressões. A escolha é 
ENSAIO - Pesquisa em Educação em Ciências

nossa, nós devemos saber onde queremos chegar. Se eu sei menos que meu colega, em exames posso provar o contrário. Gostei muito de fazer sínteses, colocar minhas idéias, as dos colegas e recolher o que sobrava de bom. Gostei também de estudar a história da Mecânica, de trabalhar com as novas idéias e de mudar de opinião a cada aula."

"Gostei de estudar diferentes modelos de interpretação dos fenômenos. Os conteúdos foram explorados sem pressões e sem 'decorebas'. Não somos obrigados a 'engolir' teorias. Aqui, cada um pensa do seu jeito sem ser recriminado. Tudo é aceito, isto é, respeitado. Estar perdida no início até me ajudou a aprender a buscar, através das pesquisas, solução para minhas dúvidas. Aprendi que na vida profissional devemos antes de tudo aceitar as opiniões dos alunos e trabalhar a partir delas para fazer com que eles cresçam. Como vamos avaliar o potencial de uma pessoa através de um número? Cada um é responsável pela sua aprendizagem."

"Gostei de poder expor as idéias em pequeno e grande grupo sem ser criticado. Aprendi a questionar o que nos é dado. Gostei do sistema de nota igual para todos, pois não nos sentimos pressionados em chegar ao final do semestre e ter que provar ao professor que sabemos toda a matéria."

"Não me importei com a nota já que minha dedicação concentrou-se em querer aprender. Gostei das aulas, [porque] mesmo [quando] explicava, o professor nunca dava certeza de nada, deixando o aluno na expectativa. Muitas perguntas ficam na nossa cabeça."

"Gostei de ter liberdade. Me senti valorizado, pois controlei meu estudo e não fui um escravo da matéria. É um pouco difícil dizer o que aprendi, pois continuo um pouco confuso. Não se preocupar com a nota foi a [melhor] parte, pois nunca gostei de ser avaliado com nota por que acredito que assim acabamos nos tornando dependentes de um avaliador."

"Uma das coisas que mais gostei foi poder responder às questões sem me preocupar com o certo e o errado, de ir atrás respostas. [Somente] agora, nas últimas aulas, que eu mais compreendi. No início do semestre eu estava totalmente perdida, imagina se houvesse uma prova! Do primeiro dia até agora cresci bastante."

\section{5 - ANÁLISE}

Coerente com uma perspectiva evolutiva do conhecimento (inclusive profissional), a postura avaliativa aqui descrita pode ser vista como situada em uma escala de complexidade crescente dos diferentes níveis de avaliação pela qual um professor pode desenvolver-se profissionalmente. Tal escala, constituindo uma hipótese de progressão (García e Porlán, 2000), inicia com uma postura de avaliação centrada na memorização mecânica de conceitos, passa por diversos estágios intermediários e, de acordo com os pressupostos teóricos adotados aqui (uma perspectiva critica, complexa, evolutiva e construtivista do conhecimento), chega aos níveis mais avançados nos quais não existe relação entre a avaliação e a atribuição de notas porque estas não existem ou não são necessárias no processo educativo.

O Quadro nํ2, abaixo, apresenta uma proposta de explicitação desta evolução. Aescala está estruturada de tal forma que o Nível 1 representa o nível mais baixo de avaliação, em retrocesso (pelo menos do ponto de vista dos debates no meio educativo), enquanto que o Nível 7 representa o estágio de referência desejável de acordo com nossos pressupostos. $A$ análise da validade dessa escala, contrastada com os dados apresentados nessa e em outras pesquisas pode ser útil para caracterizar diferentes posturas avaliativas, identificando assim quais níveis (e práticas) são evolutivamente mais coerentes com os pressupostos adotados e permitindo a definição de estratégias de evolução das posturas avaliativas. 
Quadro no 2 - Níveis de evolução nas práticas avaliativas

\begin{tabular}{|c|c|}
\hline Nível & Prática de avaliação \\
\hline 1 & $\begin{array}{l}\text { Existe relação entre a avaliação e as notas e estas são atribuídas valorando apenas à capodidade } \\
\text { de reprodução mecânica e memorística de elementos conceituais. }\end{array}$ \\
\hline 2 & $\begin{array}{l}\text { Existe relação entre a avaliação e as notas. Estas são atribuídas fazendo-se alusão apenas a } \\
\text { elementos conceituais, embora enfatize-se a capacidade de compreensão, de transferência, de } \\
\text { generalização e de aplicação desses conceitos a novos contextos. }\end{array}$ \\
\hline 3 & $\begin{array}{l}\text { Existe relação entre a avaliação e as notas. Estas são atribuídas fazendo-se alusão a mais } \\
\text { elementos (procedimentais e atitudinais) do que o domínio de conceitos (participação, interesse, } \\
\text { freqüência, etc.). De qualquer forma a avaliação ainda é fundamentalmente somativa e } \\
\text { sancionadora. }\end{array}$ \\
\hline 4 & $\begin{array}{l}\text { É atribuída uma nota e esta tem relação com o compromisso e com a qualidade dos trabalhos e } \\
\text { com as idéias finais apresentadas, diferenciando-se as notas entre os alunos, por exemplo, através } \\
\text { da auto-avaliação individual e coletiva dos próprios alunos e a avaliação do professor. Procede-se a } \\
\text { avaliação do crescimento dos alunos e do desenvolvimento das aulas. Começa a haver uma } \\
\text { diferenciação entre avaliação e classificação dos alunos. }\end{array}$ \\
\hline 5 & $\begin{array}{l}\text { É atribuída uma nota, mas esta mede apenas a realização ou não das atividades, ou seja o } \\
\text { compromisso com os trabalhos e não as idéias finais apresentadas. Havendo mais trabalho e mais } \\
\text { compromisso, maior nota mas sem valorar a qualidade dos trabalhos. As notas entre os alunos são } \\
\text { diferenciadas segundo a auto-avaliação individual e coletiva dos próprios alunos que leva em conta, } \\
\text { preponderantemente, os aspectos atitudinais e procedimentais }\end{array}$ \\
\hline 6 & $\begin{array}{l}\text { Se diferencia classificação da avaliação, por isso não existe relação entre avaliação e a atribuição } \\
\text { de notas. Mas, como esta é necessária (o sistema obriga) atribui-se uma nota igual para todos (que } \\
\text { apresentam freqüência, quando o sistema obriga este controle, e compromisso com as atividades) } \\
\text { sem considerar a qualidade dos trabalhos ou as idéias finais apresentadas. Procede-se a avaliação } \\
\text { e a auto-avaliação do crescimento dos alunos e do desenvolvimento das aulas. A avaliação é } \\
\text { eminentemente formativa. }\end{array}$ \\
\hline 7 & $\begin{array}{l}\text { Não existe relação entre a avaliação e a atribuição de notas porque estas não existem ou não são } \\
\text { necessárias no processo educativo, embora se avalie o processo de crescimento dos alunos e o } \\
\text { desenvolvimento das aulas. A ênfase reside basicamente na auto-avaliação. }\end{array}$ \\
\hline
\end{tabular}




\section{REFERÊNCIAS BIBLIOGRÁFICAS}

ASSIS, A.K.T. (1998). Mecânica Relacional. Campinas (SP): Editora da UNICAMP.

CUBERO, R. (1989). Como trabajar con las ideas de los alumnos. Sevilha: Díada.

GARCÍA, J.E. (1998). Una teoria alternativa de los contenidos escolares. Sevilha: Díada.

GARCÍA, J.E. \& PORLÁN, R. (2000) Teoria e prática na ação docente: uma teoria do conhecimento profissional. In: HARRES, J.B.S. (org.). Ensino de ciências: teoria e prática docente. Cadernos Pedagógicos, no 3. Lajeado: UNIVATES Editora. p.7-42.

HARRES, J.B.S. (1999). Concepções de professores sobre a natureza da ciência. Porto Alegre: PUCRS. Tese de doutorado não publicada.

HARRES, J.B.S. (2001). Evolução do conhecimento prévio como estratégia para o desenvolvimento profissional: o caso das concepções sobre força e movimento de futuros professores para o ensino médio (14 a 17 anos). Alicante: $2^{\underline{a}}$ Reunión Novirtual de la Red IRES.

HARRES, J.B.S. (2002a). Avaliação não classificatória e auto-avaliação: uma estratégia para desenvolvimento profissional de futuros professores. La Laguna (Espanha): Atas del XX Encuentros sobre Didacticas de las Ciencias Experimentales, p. 707-715.

HARRES, J.B.S. (2002b). Desenvolvimento histórico da dinâmica: referente para a evolução das concepções dos estudantes sobre força e movimento. I Encuentro Iberoamericano sobre Investigación Básica en Enseñanza de las Ciencias. Burgos: Universidade de Burgos.

HARRES, J.B.S. (2003). A física da força impressa: queres que eu responda o que eu sei ou o que me ensinaram na escola? XV Simpósio Nacional de Ensino de Física, Curitiba.

HARRES, J.B.S. e PIZZATO, M.C. (2003) Laboratórios de ensino: investigando problemas práticos profissionais. Trabalho apresentado na VI Escola de Verão de Práticas de Ensino de Biologia, Física e Química, Niterói.

MARTÍN DEL POZO, R. e PORLÁN, R. (2000). Materiales curriculares para hacer evolucionar las concepciones de los futuros maestros sobre la enseñanza de los contenidos escolares de ciencias. Madrid: Actas de los XIX Encuentros de las Didácticas de las Ciencias Experimentales, 397-401. 
MORAES, A.M. e MORAES, I.J. (2000). A avaliação conceitual de força e movimento. Revista Brasileira de Ensino de Física 22 (2), 1-15.

NEVES, M.C.D. E SAVI, A.A. (1999). A sobrevivência do alternativo: uma pequena digressão sobre mudanças conceituais que não ocorrem no ensino de física. Campinas: Atas do II Encontro Nacional de Pesquisa em Educação em Ciências.

NOVOA, A . (2001). O professor se forma na escola. Revista Nova Escola, maio.

PEDUZZI, L. (1996). Física aristotélica: por que não considerá-la no ensino? Caderno Catarinense de Ensino de Física 13 (1), 48-63.

PEDUZZI, L. e ZYLBERSTAJN, A. (1997). La física de la fuerza impresa y sus implicaciones para le enseñanza de la mecánica. Ensenãnza de las Ciencias, 15 (3), 351-359.

PETROSINO, J. (2000). Cuanto duran los aprendizajes adquiridos? El dudoso ideal del conocimiento impecable. Buenos Aires: Novedades Educativas.

PORLÁN, R. \& HARRES, J.B.S. (1999) La epistemología evolucionista de Stephen Toulmin y la enseñanza de las ciencias. Investigación en la Escuela 39, 17-26.

PORLÁN, R. \& RIVERO, A. (1998). El conocimiento de los profesores. El caso del área de ciencias. Sevilha: Díada.

SOLANO, I.; JIMÉNEZ-GÓMEZ, E.; MARÍN, N. (2000). Análisis de la metodología utilizada en la búsqueda de "lo que el alumno sabe" sobre fuerza. Enseñanza de las Ciencias 18 (2), 171-188.

THORTON, R.K. e SOKOLOFF, D.R. (1998). Assessing student learning of Newton' s laws: the force and motion conceptual evaluation and the evaluation of active learning laboratory and lecture curricula. American Journal of Physics 66(4).

VILLANI, A. e POLIDO FERREIRA, M. (1997). As dificuldades de uma professora inovadora. Caderno Catarinense de Ensino de Física 14 (2),115-145.

Data de recebimento: 18/12/2003

Data de aprovação: 31/05/2004 